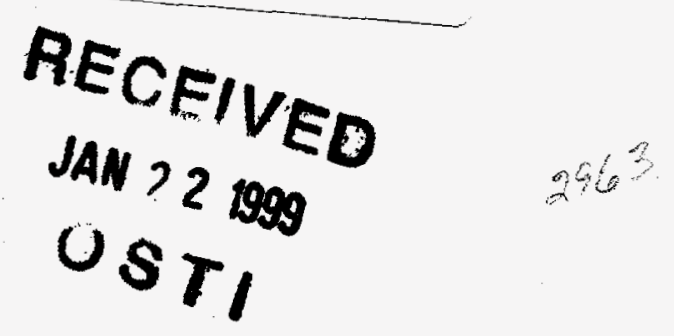

\title{
Comparison of Analytical and Experimental Effectiveness of Four-Row Plate-Fin-Tube Heat Exchangers with Water, R-22, and R-410A
}

\author{
T. D. Chen \\ J. C. Conklin \\ V. D. Baxter
}

to be presented at ASME Winter Annual Meeting Anaheim, California November 15, 1998

Prepared for the

Oak Ridge National Laboratory

Oak Ridge, Tennessee 37831

managed and operated by

Lockheed Martin Energy Research Corporation

for the

U.S. Department of Energy

under Contract DE-AC05-96OR22464

"This submitted manuscript has been authored by a contractor of the U.S. Government under contract No. DE-AC05-96OR22464. Accordingly, the U.S. Government retains a nonexclusive, loyaltyfree license to publish or reproduce the published form of this contribution, or allow others to do so, for U.S. Government purposes." 


\section{DISCLAIMER}

This report was prepared as an account of work sponsored by an agency of the United States Government. Neither the United States Government nor any agency thereof, nor any of their employees, make any warranty, express or implied, or assumes any legal liability or responsibility for the accuracy, completeness, or usefulness of any information, apparatus, product, or process disclosed, or represents that its use would not infringe privately owned rights. Reference herein to any specific commercial product, process, or service by trade name, trademark, manufacturer, or otherwise does not necessarily constitute or imply its endorsement, recommendation, or favoring by the United States Government or any agency thereof. The views and opinions of authors expressed herein do not necessarily state or reflect those of the United States Government or any agency thereof. 


\section{DISCLAIMER}

Portions of this document may be illegible in electronic image products. Images are produced from the best available original document. 


\title{
COMPARISON OF ANALYTICAL AND EXPERIMENTAL EFFECTIVENESS OF FOUR-ROW PLATE-FIN-TUBE HEAT EXCHANGERS WITH WATER, R-22 AND R-410A
}

\author{
Tony D. Chen, James C. Conklin and Van D. Baxter \\ Oak Ridge National Laboratory \\ MS 6070, Building 3147 \\ Oak Ridge, TN 37831-2008 \\ U. S. A.
}

\begin{abstract}
The analytical solutions of heat exchanger effectiveness for four-row crosstlow, cross-countertlow and cross-paralleltlow have been derived in the recent study. The main objective of this study is to investigate the effect of heat exchanger tlow configuration on thermal performance with refrigerant mixtures. Difference of heat exchanger effectiveness for all flow arrangements relative to an analytical many-row solution has been analyzed. A comparison of four-row cross countertlow heat exchanger effectiveness between analytical solutions and experimental data with water, R-22, and R-410A is presented.
\end{abstract}

\section{NOMENCLATURE}

A : Heat transfer surface area, $\left(\mathrm{m}^{2}\right)$

C : Capacity rate, (KW/C)

$\mathrm{k} \quad$ : Quantity defined in Equation (3)

LMTD : Log Mean Temperature Difference, $\left({ }^{\circ} \mathrm{C}\right)$

NTU : Number of Transfer Units

Q : Heat transfer rate, $(\mathrm{kW})$

$\mathrm{t} \quad$ : Temperature of fluid tlow $\mathrm{R},\left({ }^{\circ} \mathrm{C}\right)$

$\mathrm{T} \quad$ : Temperature of fluid flow $\mathrm{A},\left({ }^{\circ} \mathrm{C}\right)$

U : Overall heat transter coefficient of heat exchanger, $\left(\mathrm{kW} / \mathrm{m}^{2} .{ }^{\circ} \mathrm{C}\right)$

$x \quad$ : Coordinate in the fluid flow A direction

$y \quad$ : Coordinate in the fluid tlow $\mathrm{R}$ direction

$\mathrm{C} p$ : Effective specific heat in two-phase region, (kJ/kg. ${ }^{\circ} \mathrm{C}$ )

C* : Ratio of minimum capacity rate to maximum capacity rate

Greek Letters

$\Delta \quad$ : Difference between two temperatures

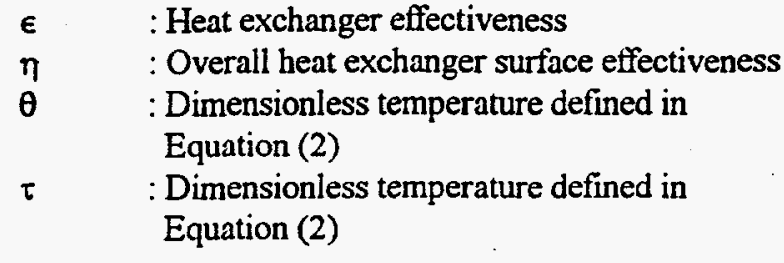

Subscripts

$0 \quad$ : Flow condition at the air or refrigerant inlet

1 : State at end of Row 1

2 : State at end of Row 2

3 : State at end of Row 3

$4 \quad$ : State at end of Row 4

A : Fluid flow A

ana : Analytical solutions

cc : Cross counterflow

cf : Counterflow

cp : Cross parallel flow

is : Crosstlow

exit : Heat exchanger exit

exp : Based on experimental data

$\min :$ Minimum

$\max :$ Maximum

$\mathrm{R} \quad$ : Fluid flow $\mathrm{R}$

\section{INTRODUCTION}

The Log Mean Temperature Difference (LMTD) approach to heat exchanger analysis is useful when the inlet and outlet temperatures are known or are easily determined. The LMTD is readily calculated, and heat flow, surface area, or overall heat transfer coefficient may then be determined. When the inlet or exit temperatures are to be determined for a given heat exchanger, the analysis frequently involves an iterative procedure. In these cases the analysis is performed more easily by utilizing a method based on the effectiveness of the heat exchanger in transferring a given amount of heat. 
The effectiveness method also offers many advantages for analysis of problems in which a comparison between various types of heat exchangers must be made for selecting the type best suited to accomplish a particular heat transfer objective.

The governing equation for the crossflow heat exchangers with both fluids unmixed was first obtained by Nusselt (1911) and Mason (1955). Nusselt used an infinite series and Mason used the Laplace transform. Baclic (1978) gave an approximate solution for crossflow heat exchangers with two unmixed fluids based on modified Bessel functions of the first kind. Stevens (1956) and Fernandez (1956) contributed substantially to the theory of the multipass cross-countertlow and crossparallelflow heat exchangers. They derived the temperature distributions for one-, two-, and three-row cross-counterflow and cross-paralleltlow heat exchangers with refrigerant-side mixed and air-side unmixed. Nicole (1972) studied the mean temperature difference in crossflow heat exchangers applied to multipass air-cooled tin-and-tube units with a finite number of rows. He listed the temperature distribution for cross-counterflow heat exchangers up to six rows. However, due to some typing errors on the effectiveness formulas, and unavailability of any further publications of his work, results could not be compared. Domingos (1969) presented a general method to calculate the total effectiveness and intermediate temperatures of assemblies of heat exchangers. His equations for predicting the effectiveness of multi-row crosstlow heat exchangers were unnecessarily complex tor the simpler geometries considered here.

In this work, an extended derivation of heat exchanger effectiveness for four-row configuration based on Stevens (1956), and Stevens et al., (1957) is presented. The temperature distribution at the exit of each row on the retiigerant-side is derived, for crosstlow, cross-countertlow and cross-paralleltlow heat exchanger configurations. The loss of effecliveness relative to the countertlow has been analyzed for the three heat exchanger configurations.

\section{MATHEMATICAL MODELS}

\section{Effectiveness of Four-Row Crossflow Heat Exchangers.}

Expanding the Stevens et al. (1957) derivation for one-pass, three-row case, one can write, for Row 4 (as shown in Figure 1):

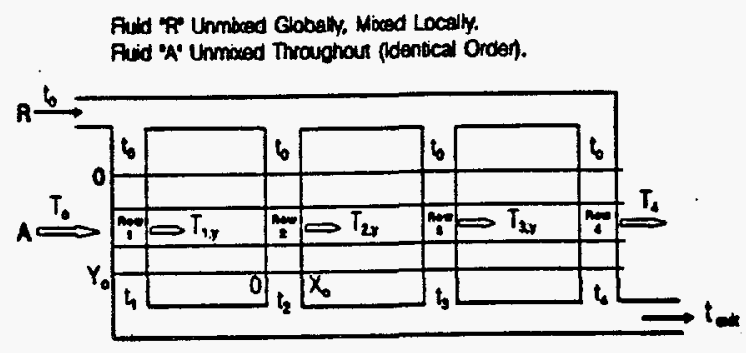

Figure 1. Geometry of a four-row crossflow heat exchanger.

$$
\theta_{4}=k \tau_{4}+(1-k) \theta_{3}
$$

where, $\theta$ and $\tau$ are dimensionless temperatures defined as

$$
\theta=\frac{T-T_{0}}{t_{0}-T_{0}}, \tau=\frac{t-T_{0}}{t_{0}-T_{0}}
$$

and

$$
k=1-e^{-N \pi U_{1}} \text {. }
$$

with

$$
N T U_{A}=\frac{\left(U_{y_{0}} x_{0} \eta \eta\right.}{C_{A}}
$$

Here, NTU $_{A}$ is the Number of Transfer Units, and $C_{A}$ is the heat capacity rate (the product of mass flow rate and specific heat) of flow $A, \eta$ is the surface effectiveness (for finned-tube heat exchangers), defined as $\eta=Q /(U A \cdot L M T D)$, where $Q$ is the total heat exchange rate, $U$ is the overall heat transfer coefficient, and $A$ is the total heat transfer area of the heat exchanger.

Since the local energy balance equation can be written as

$$
C_{A} \frac{d y}{y_{0}}\left(\theta_{4}-\theta_{3}\right)=C_{R} d \tau_{4}
$$

and $\theta_{3}$ (Stevens et al., 1957) can be expressed as 


$$
\begin{gathered}
\theta_{3}=k\left[1+2 k^{2} C \cdot \frac{y}{y_{0}}-k^{3} C \cdot \frac{y}{y_{0}} \cdot \frac{1}{2} k^{4}(C)^{2} \frac{y^{2}}{y_{0}^{2}}\right] e^{+c^{*} \frac{y}{y_{0}}} \\
\cdot(1-k) \theta_{2}
\end{gathered}
$$

where, $C^{*} \equiv C_{A} / C_{R}$, and $\theta_{2}$ is given (Stevens et al., 1957) as

$$
\theta_{2}=k\left[e^{-k c \cdot \frac{y}{y_{0}}}+k^{2} C \cdot \frac{y}{y_{0}} e^{-k \cdot \frac{y}{y_{0}}}\right] \cdot k(1-k) e^{-k \cdot \frac{y}{y_{0}}(7)}
$$

one can solve for $\tau_{4}$, the temperature distribution of fluid $R$ leaving row 4 from Equation (5) with the known $\theta_{3}$ in Equation (6) and $\theta_{2}$ in Equations (7),

$$
\begin{gathered}
\tau_{4}=\left[1 \cdot\left(3-3 k+k^{2}\right) C \cdot k^{2} \cdot \frac{1}{2}(3-2 k) C \cdot k^{4} \cdot \frac{1}{6} C \cdot k^{6}\right] \\
\times e^{-k c}
\end{gathered}
$$

Defining the heat exchanger effectiveness $\epsilon$ (Kays \& London, 1984) as the ratio of actual heat transfer to the maximum possible heat transfer with infinite heat transfer area, or equivalently as the ratio of the temperature change of the minimum capacity rate fluid to the maximum temperature difference between the two fluids in heat exchanger. Thus, from the definition of $\tau$, the effectiveness $\epsilon_{\mathrm{cs}}$ of a four-row crossflow heat exchanger is the following

$$
\begin{gathered}
\epsilon_{\mathrm{cst}}=\frac{C_{A} \Delta T_{A}}{C_{\min } \Delta T_{\max }}-\frac{C_{R} \Delta T_{R}}{C_{\min } \Delta T_{\max }} \cdot \frac{C_{R}}{C_{\min }}\left[\frac{t_{0}-\frac{t_{t}+t_{2}+t_{3}+t_{4}}{4}}{t_{0}-T_{0}}\right] \\
\cdot \frac{C_{R}}{C_{\min }}\left[1-\frac{\tau_{1}+\tau_{2}+\tau_{3}+\tau_{4}}{4}\right] .
\end{gathered}
$$

The analytical solution of this $\epsilon_{4}$, designated as $\epsilon_{\mathrm{cs}}$, is shown in Table 1.

Correlations for calculating the approximate effectiveness of crosstlow heat exchanger with both fluids unmixed include:

Hiller and Glicksman (1976),

$$
\epsilon_{c \sigma^{*}} \cdot\left(1+0.047 C^{\cdot}\right) N T U^{0.036 C^{*}}
$$

and Hoiman (1986),

$$
\epsilon_{C S}=1-\exp \left(-\frac{1-\exp \left(-C^{\cdot} N T U^{0.78}\right)}{C \cdot N T U^{-0.22}}\right)
$$

\section{Effectiveness of Four-Row Cross-Parallelfow Heat Exchangers.}

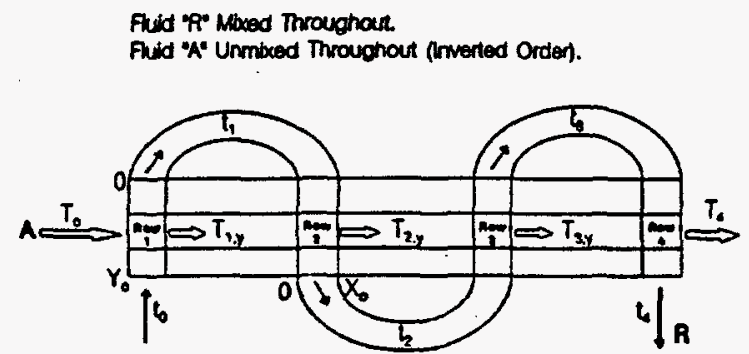

Figure 2. Flow configuration of a four-row crossparallelflow heat exchanger.

The technique used for solving the temperature of fluid $R$ leaving row 4 can be applied to four-row crossparailelflow (as shown in Figure 2) configurations. The temperature distribution of fluid $R$ leaving row 4 can be obtained as

$$
\begin{gathered}
\tau_{4}=\left[\left(1-\frac{k}{2}\right)^{3}\right] e^{+4 k \cdot R} \cdot\left[2 k^{2}\left(1-\frac{k}{2}\right)^{2} C^{\cdot} \cdot k\left(1-\frac{k}{2}\right)\right] e^{-* C^{*}} \\
\cdot\left[\frac{k}{8}\left(4-2 k+k^{2}\right)\right]
\end{gathered}
$$

By the definition of heat exchanger effectiveness and $\tau$, one can write the effectiveness of a four-row cross-parallelflow (or called cocrossflow) heat exchanger in the following form, 
Table 1. Summary of heat exchanger effectiveness of four-row crosstlow, cross-parallellow, and cross-countertlow heat exchangers.

Crossflow

$\epsilon_{c t}=\frac{C_{R}}{C_{\min }}\left\{1-\frac{e^{+4 k C^{*}}}{4}-\frac{1+4 k^{2} C^{\cdot} e^{-4 k C^{*}}}{4}-\frac{\left[1+4 k^{2}(2-k) C \cdot+8 C^{*^{2}} k^{4}\right] e^{-4 k \cdot}}{4}-\frac{\left[1+4\left(3-3 k+k^{2}\right) C k^{2}+8(3-2 k)(C)^{2} k^{4}+\frac{32}{3}(C)^{3} k^{6}\right] e^{-4 k C^{*}}}{4}\right\}$

Cross-parallelflow

$$
\epsilon_{c p r}=\frac{C_{R}}{C_{\min }}\left(1-\left(1-\frac{k}{2}\right)^{3} e^{-4 k C^{*}} \cdot\left[2 k^{2}\left(1-\frac{k}{2}\right) C^{\cdot}+k\left(1-\frac{k}{2}\right)\right] e^{-2 k C^{\bullet}}-\left[\frac{k}{8}\left(4-2 k+k^{2}\right)\right]\right\}
$$

Cross-Countertlow

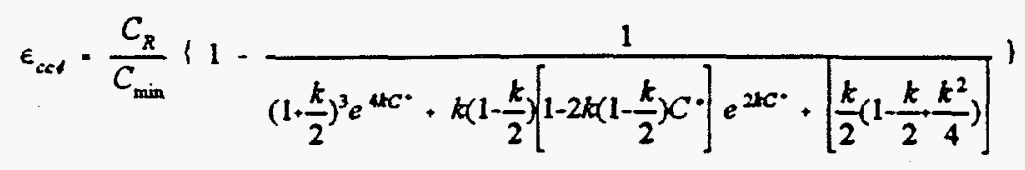

$$
\begin{gathered}
\epsilon_{\text {cor }}=\frac{C_{A} \Delta T_{A}}{C_{\min } \Delta T_{\max }}-\frac{C_{R}\left(t_{0}-t_{4}\right)}{C_{\min }\left(t_{0}-T_{0}\right)} \\
=\frac{C_{R}}{C_{\min }}\left(\tau_{0}-\tau_{4}\right)=\frac{C_{R}}{C_{\min }}\left(1-\tau_{1}\right) .
\end{gathered}
$$

\section{Effectiveness of Four-Row Cross-Countertlow Heat Exchangers.}

Similar to the crosstlow and cross-parallelliow, the temperature of fluid $R$ leaving row $I$ tor a four-row cross-countertlow (as shown in Figure 3) can be obtained as

$$
\tau_{1}=\tau_{2} e^{* C^{*}}
$$

where,

$$
\frac{1}{\tau_{2}} \cdot\left[\left(1-\frac{k}{2}\right)^{3}\right] e^{3 k \cdot} \cdot k\left(1-\frac{k}{2}\right)\left[1-2 k\left(1-\frac{k}{2}\right) C \cdot\right] e^{k \cdot}
$$

$$
+\left[\frac{k}{2}\left(1-2 k+\frac{k^{2}}{4}\right)\right] e^{\star c^{-}}
$$

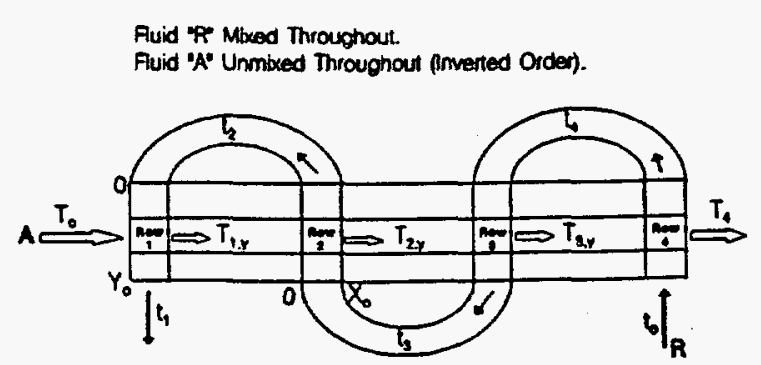

Figure 3. Flow configuration of a four-row crosscounterflow heat exchanger. 
and, by the detinition of effectiveness and $\tau$, we have

$$
\begin{gathered}
\epsilon_{c c d}=\frac{C_{A} \Delta T_{A}}{C_{\min } \Delta T_{\max }}=\frac{C_{R}\left(t_{0}-t_{1}\right)}{C_{\min }\left(t_{0}-T_{0}\right)} \\
=\frac{C_{R}}{C_{\min }}\left(\tau_{0}-\tau_{1}\right)=\frac{C_{R}}{C_{\min }}\left(1-\tau_{1}\right) .
\end{gathered}
$$

The heat exchanger effectiveness for the counterflow heat exchanger configuration given by Kays and London (1984) is

$$
\epsilon_{G f}=\frac{1-\exp [-N T U(1-C)]}{1-C^{*} \exp [-N T U(1-C)]} .
$$

\section{RESULTS AND DISCUSSION}

\section{Four-Row Crossflow Heat Exchangers.}

Table 1 shows the comparison of heat exchanger effectiveness of four-row crosstlow, crossparallelflow, and cross-countertlow heat exchangers. Figure 4(a) shows the comparison of heat exchanger effectiveness for a one-pass, four-row unmixed/unmixed calculated from Equation (9) relative to an approximate solution (Baclic, 1978). The comparison of effectiveness for four-row crosstlow is about $1.0 \%$ for the case of $C_{A} / C_{R}=1.0$ for Number of Transter Units (NTU) of 5.0. The same trend can be seen in Figure 4(b) in the case of $C_{A} / C_{R}=0.5$. Notice that Equation (11) for crosstlow with both fluids unmixed has maximums $4 \%$ and $2 \%$ less than that of the solution in the low NTU range for the cases of $C_{A} / C_{R}=1.0$ and $C_{A} / C_{R}=0.5$, respectively. Figure $5(a)$ shows the comparison of the heat exchanger effectiveness among Hiller (Equation (10)), Holman (Equation (1I)) and Baclic approximate solution (with Bessel function). Figure $5(\mathrm{~b})$ shows the departure of effectiveness relative to the Baclic approximate solution. The effectiveness calculated by Hiller correlation has about $1.0 \%$ difference compared to the Baclic approximate many-row solution for values of NTU from 2.0 to 4.0. Holman correlation has a better ( less than 1.0\%) agreement with the Baclic approximate solution for NTU greater than 1.0. The analytic solution for the heal exchanger effectiveness of crosstlow, both lluids unmixed how arrangement cannot be expressed in closed form (Kays and London, 1984). However, the Baclic approximate solutions are very close to the original work of Mason (1955) for this heat exchanger flow arrangement, according to the current study. Therefore, the Baclic approximate solution will be used as the reference for comparison.

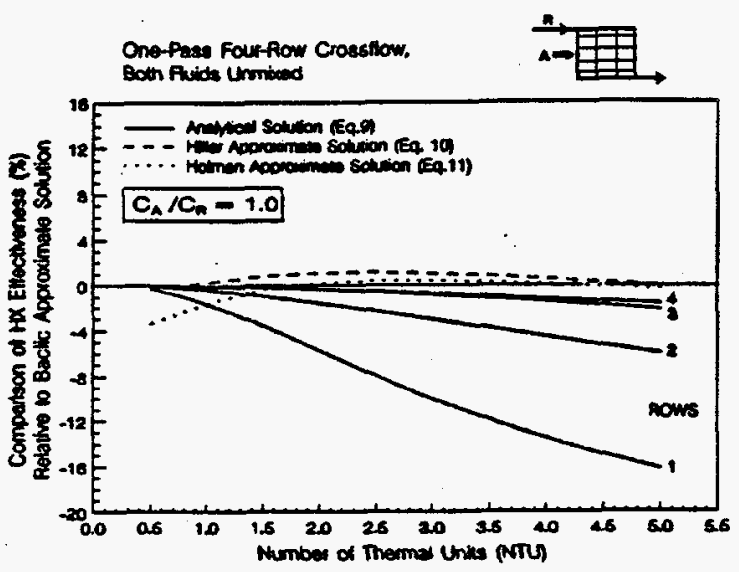

Figure 4(a). Comparison of heat exchanger effectiveness for four-row crossflow heat exchanger relative to approximate many-row solution (Baclic, 1978) for $C_{A} / C_{R}=1.0$ case.

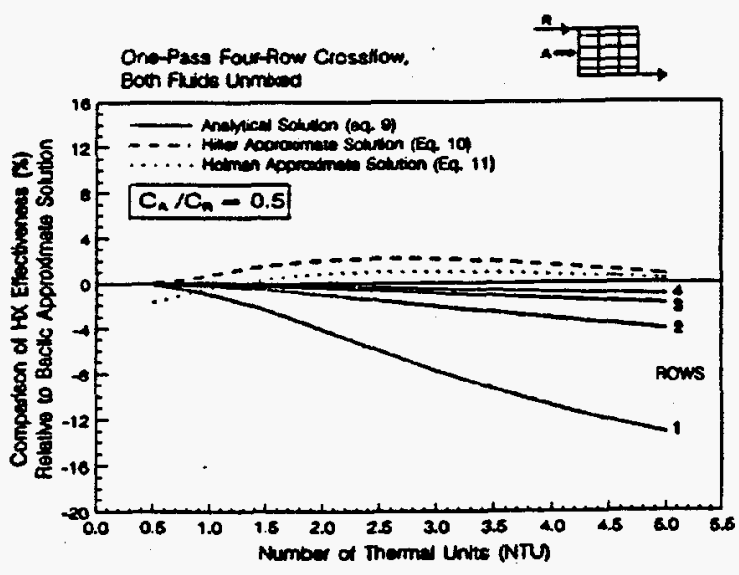

Figure (b). Comparison of heat exchanger effectiveness for four-row crossflow heat exchanger relative to approximate many-row solution (Baclic, 1978) for $C_{A} / C_{R}=0.5$ case.

\section{Four-Row Cross-Parallelflow Heat Exchangers.}

Figures $6(a)$ and $6(b)$ show the decrease of cross-parallelflow heat exchanger effectiveness relative to countertlow heat exchanger for the cases of $C_{A} / C_{R}=1.0$ and $C_{A} / C_{R}=0.5$, respectively. Unlike crossflow and cross-countertlow, the effectiveness of cross-parallelflow heat exchanger weakly decreases as the number of row increases for both $C_{A} / C_{R}=1.0$ and 0.5 cases. This is 
because as the number of rows increase, the crossparallelflow more approximatesparallelflow always has less effectiveness than countertlow or crosstlow for the same NTU.

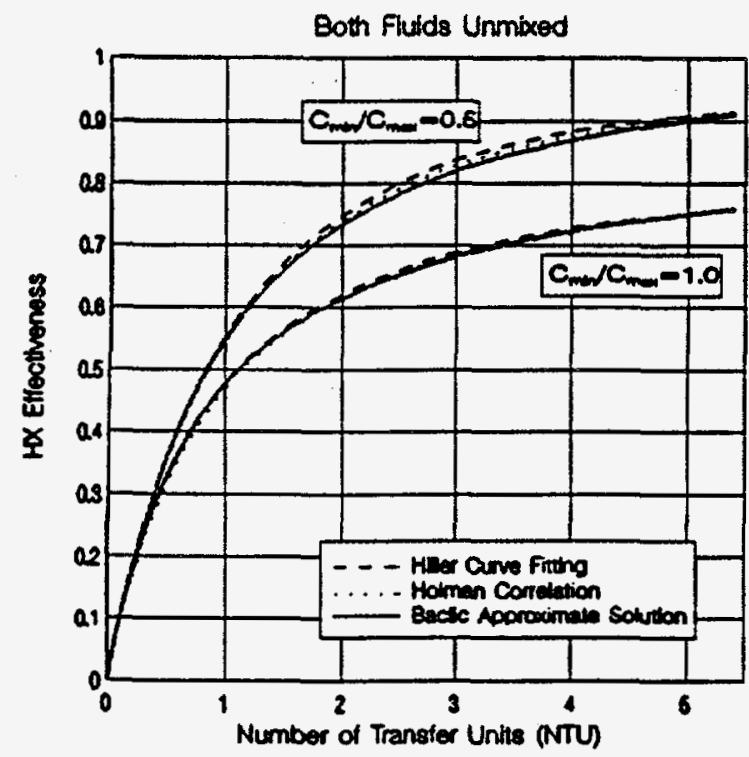

Figure 5(a). Comparison of many-row crossflow heat exchanger effectiveness among correlations.

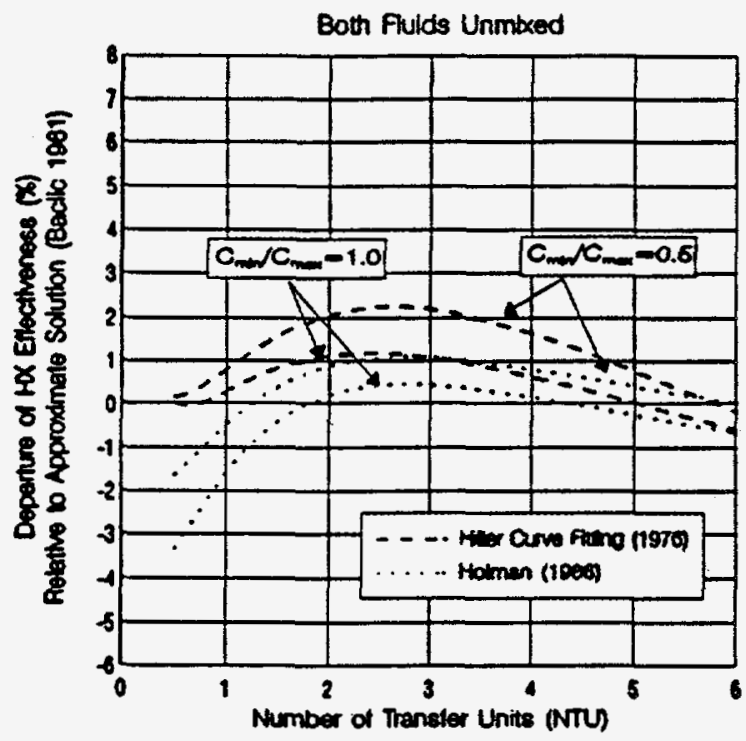

Figure 5(b). Departure of many-row crosstlow heat exchanger effectiveness relative to approximate solution (Baclic, 1978).

\section{Four-Row Cross-Counterflow Heat Exchangers.}

Figures 6(a) and 6(b) also show the decrease of cross-counterflow heat exchanger effectiveness relative to counterflow heat exchanger for the cases of $C_{A} / C_{R}=1.0$ and 0.5 , respectively. The departure of effectiveness of four-row cross-counterflow to the many-row counterflow is $3 \%$ and $1 \%$, in the case of $C_{A} / C_{R}=1.0$ and 0.5 , respectively. Results indicate that the effectiveness of four-row cross-counterflow heat exchanger is very close to the counterflow heat exchanger configuration over a wide range of capacity ratios $C_{A} / C_{R}$.

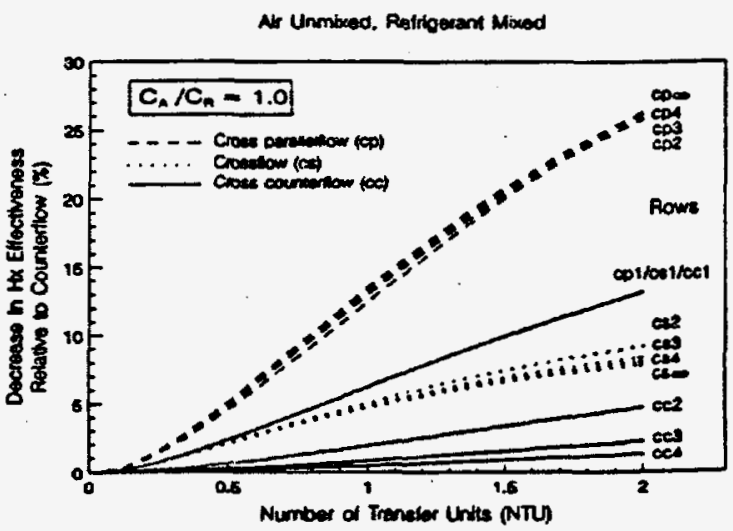

Figure 6(a). Decrease of heat exchanger effectiveness for four-row crossflow, cross-parallelflow and crosscountertlow heat exchangers for $C_{A} / C_{R}=1.0$ case.

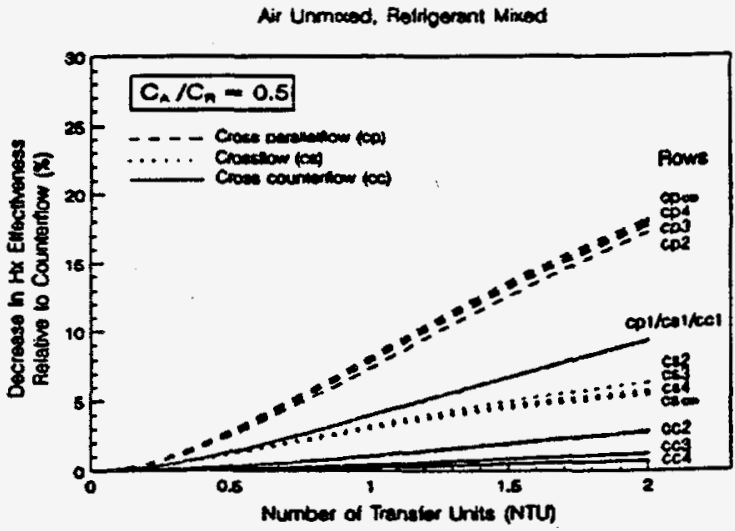

Figure 6(b). Decrease of heat exchanger effectiveness for four-row crossflow, cross-parallelflow and cross-counterflow heat exchangers for $C_{A} / C_{R}=0.5$ case. 
Experimental Data of a Four-Row CrossCounterflow Heat Exchanger.

Table 2 shows the experimental data of a fourrow, 15-fpi (fins per inch) fin-and-tube heat exchanger with water, $R-22$, and R-410A; including capacity rates, measured inlet and outlet temperatures of both fluids, and the effectiveness based on measured temperatures and analytical expression. Air inlet temperature was set to $26.7^{\circ} \mathrm{C}$ for all tests. For air-to-water tests, two sets (water inlet temperature at $10^{\circ} \mathrm{C}$ and $18^{\circ} \mathrm{C}$ ) of experiments have been conducted, and $C_{R}$ was maintained around 2.32 $\mathrm{kW} /{ }^{\circ} \mathrm{C}$; For $\mathrm{R}-22$ and $\mathrm{R}-410 \mathrm{~A}$ tests, the air-range (temperature difference between the air inlet and outlet) was set to $12.5^{\circ} \mathrm{C}\left(22.5^{\circ} \mathrm{R}\right)$. Calculation of $\epsilon_{\text {ana }}$ was based on Table $1, \epsilon_{\exp }$ was based on equation (16), and $\epsilon_{\mathrm{cf}}$ was based on Equation (17).

Figure 7 shows the experimentally determined effectiveness of this four-row inverted-order crosscounterflow heat exchanger with water, R-22 and R410A. The effective specific heat in the two-phase region, $C p$, for refrigerant $R-22$ and mixture $R-410 A$ is defined as $C p=\Delta \mathrm{h} / \Delta \mathrm{T}$. The quality of vapor entering the evaporator is about $20 \%$, and the superheat leaving the evaporator is about $3.0 \mathrm{~K}$ for all the R-22 and R-410A tests. The cooling capacity of the tests ranges from 1.5 to $10.0 \mathrm{~kW}(5.12$ to $34.13 \mathrm{kBtu} / \mathrm{hr}$ ), and the average effectiveness of this evaporator is about 0.7 for all tested media, and could be as low as 0.4 when capacity ratio approaches 1.0 with low NTU around 0.5 .

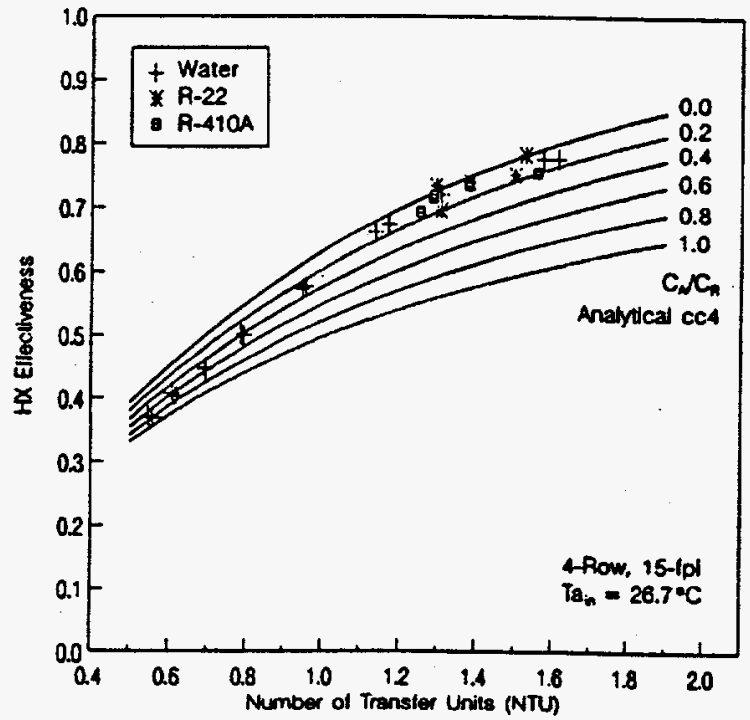

Figure 7. Comparison of heat exchanger effectiveness of a four-row cross-counterllow (inverted-order) heat exchanger among water, $R-22$ and $R-410 \mathrm{~A}$.
Figure 8 shows a comparison of experimental and analytical heat exchanger effectiveness of this fourrow, 15-fpi, inverted-order cross-counterflow evaporator. The uncertainty of $\epsilon_{\exp }$ is 0.01 as calculated by the propagation error method proposed by Kline and McClintock (1953). The differences between them range from $-3.3 \%$ to $+3.0 \%$ in the tested capacity range. Thus, the analytical predictions of effectiveness are in excellent agreement with the experimental values.

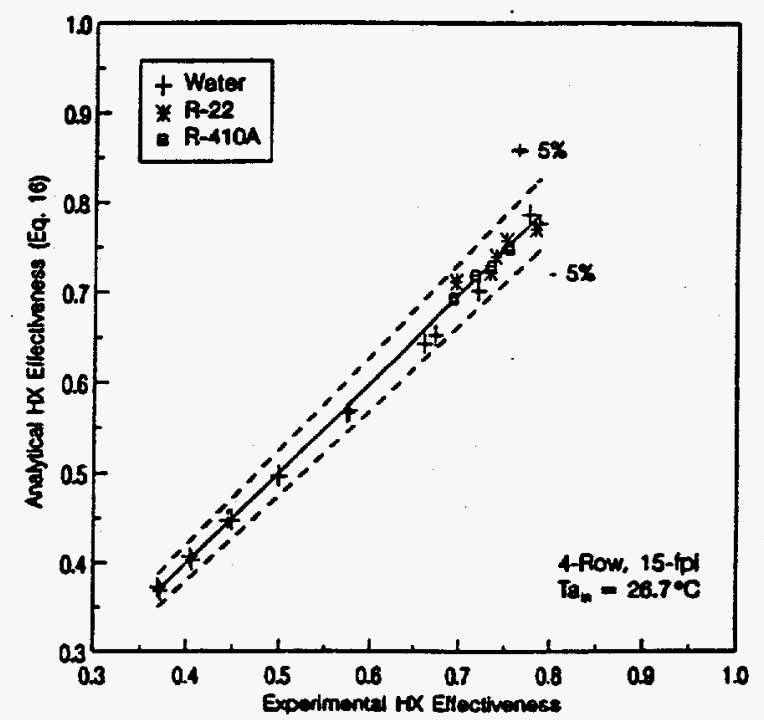

Figure 8. Comparison of four-row cross-counterflow heat exchanger effectiveness between experimental data and analytical solutions (Eq. 16).

\section{CONCLUSIONS}

The analytical heat exchanger effectiveness for four-row crossflow, cross-parallelflow, and crosscounterflow configurations have been derived in the recent study and compared with existing approximate solutions in the literature. The two approximate solutions of Holman (1986) and Hiller (1976) were within $2 \%$ for physically interesting values of NTU greater than 0.5 .

The calculated four-row heat exchanger effectiveness for cross-counterflow is very close to the approximate many-row solution, indicating that the fourrow cross-counterflow heat exchanger is approximately counterflow.

The experimental and analytical heat exchanger effectiveness of a four-row, 15-fpi, inverted-order crosscounterflow evaporator agreed very well with each other. The difference between them ranges from $-3.3 \%$ to $+3.0 \%$ for the tested cooling capacity range of $1.5 \mathrm{~kW}$ to $10.0 \mathrm{~kW}(5.12$ to $34.13 \mathrm{kBtu} / \mathrm{hr})$ and over a wide range of capacity flow rate ratios and NTU values from 0.5 to 2.0. 
Table 2. Comparison of analytical and experimental effectiveness of a fin-and-tube cross-counterflow heat exchanger with water, R-22 and R-410A.

\begin{tabular}{|c|c|c|c|c|c|c|c|c|c|}
\hline $\begin{array}{l}\mathrm{C}_{\hat{A}} \\
\left(k W / W^{\circ} \mathrm{C}\right)\end{array}$ & $\begin{array}{l}C_{R} \\
\left(k W / /^{\circ} C\right)\end{array}$ & $\begin{array}{l}\mathrm{UA} \\
\left(\mathrm{kW} /{ }^{\circ} \mathrm{C}\right)\end{array}$ & $\begin{array}{l}\mathrm{T}_{\mathrm{Al}} \\
\left({ }^{\circ} \mathrm{C}\right)\end{array}$ & $\begin{array}{l}T_{A 4} \\
\left({ }^{\circ} \mathrm{C}\right)\end{array}$ & $\begin{array}{l}t_{R 1} \\
\left({ }^{\circ} \mathrm{C}\right)\end{array}$ & $\begin{array}{l}t_{\mathrm{RA}_{4}} \\
\left({ }^{\circ} \mathrm{C}\right)\end{array}$ & $\epsilon_{\mathrm{eq}}$ & $\epsilon_{2 \mathrm{~m}}$ & $\epsilon_{d}$ \\
\hline \multicolumn{10}{|l|}{ Water } \\
\hline 0.213 & 2.320 & 0.336 & 26.7 & 13.9 & 11.5 & 10.4 & 0.79 & 0.78 & 0.78 \\
\hline 0.387 & 2.332 & 0.506 & 26.6 & 14.9 & 12.2 & 10.4 & 0.72 & 0.70 & 0.70 \\
\hline 0.545 & 2.323 & 0.639 & 26.5 & 15.8 & 12.9 & 10.6 & 0.67 & 0.65 & 0.66 \\
\hline 0.807 & 2.325 & 0.766 & 26.9 & 17.6 & 13.8 & 10.7 & 0.57 & 0.57 & 0.57 \\
\hline 1.061 & 2.322 & 0.843 & 26.6 & 18.6 & 14.2 & 10.5 & 0.50 & 0.50 & 0.50 \\
\hline 1.296 & 2.316 & 0.900 & 26.6 & 19.4 & 14.6 & 10.6 & 0.45 & 0.45 & 0.45 \\
\hline 1.554 & 2.329 & 0.959 & 26.7 & 20.3 & 15.2 & 10.8 & 0.40 & 0.41 & 0.41 \\
\hline 1.787 & 2.326 & 0.998 & 26.6 & 21.2 & 16.1 & 10.8 & 0.37 & 0.37 & 0.37 \\
\hline 0.180 & 2.317 & 0.291 & 27.9 & 20.4 & 18.8 & 18.2 & 0.78 & 0.79 & 0.79 \\
\hline 0.532 & 2.314 & 0.605 & 26.7 & 21.1 & 19.4 & 18.2 & 0.66 & 0.64 & 0.64 \\
\hline 0.810 & 2.314 & 0.775 & 26.9 & 21.4 & 19.3 & 17.4 & 0.58 & 0.57 & 0.57 \\
\hline 1.041 & 2.313 & 0.820 & 26.6 & 22.5 & 20.2 & 18.4 & 0.50 & 0.50 & 0.50 \\
\hline 1.274 & 2.315 & 0.882 & 26.7 & 23.0 & 20.4 & 18.3 & 0.44 & 0.45 & 0.45 \\
\hline 1.525 & 2.317 & 0.928 & 26.7 & 23.3 & 20.6 & 18.4 & 0.41 & 0.40 & 0.40 \\
\hline 1.777 & 2.316 & 0.975 & 26.9 & 23.7 & 20.7 & 18.3 & 0.37 & 0.37 & 0.37 \\
\hline \multicolumn{10}{|l|}{ R-22 } \\
\hline 0.353 & 3.265 & 0.530 & 26.7 & 14.2 & 11.5 & 10.1 & 0.75 & 0.76 & 0.76 \\
\hline 0.388 & 5.687 & 0.593 & 26.7 & 14.1 & 11.4 & 10.6 & $0.78^{\circ}$ & 0.77 & 0.77 \\
\hline 0.554 & 34.24 & 0.717 & 26.7 & 14.1 & 9.6 & 9.8 & 0.73 & 0.72 & 0.72 \\
\hline 0.532 & 11.20 & 0.736 & 26.7 & 14.1 & 10.2 & 9.6 & 0.74 & 0.74 & 0.74 \\
\hline 0.670 & 6.522 & 0.876 & 26.7 & 14.1 & 8.6 & 9.9 & 0.70 & 0.71 & 0.71 \\
\hline \multicolumn{10}{|l|}{$R-110 A$} \\
\hline 0.365 & 1.612 & 0.569 & 26.7 & 14.1 & 12.7 & 10.0 & 0.76 & 0.75 & 0.75 \\
\hline 0.501 & 4.754 & 0.691 & 26.7 & 14.0 & 10.7 & 9.4 & 0.74 & 0.73 & 0.73 \\
\hline 0.638 & 26.71 & 0.822 & 26.6 & 14.3 & 9.7 & 9.4 & 0.72 & 0.72 & 0.72 \\
\hline 0.791 & 6.260 & 0.992 & 26.7 & 14.4 & 10.5 & 9.0 & 0.69 & 0.69 & 0.70 \\
\hline
\end{tabular}

\section{REFERENCES}

Baclic, B. S., 1978, "A Simplitied Formula for CrossFlow Heat Exchanger Effectiveness," Jonmal of Heat Transfer, Vol. 100, pp. 746-747.

Domingos, J. D., 1969, "Analysis of Complex Assemblies of Heat Exchangers," International Joumal of Heat and Mass Transfer, Vol. 12, pp. 537-548.

Fernandez, J., 1956, Mean Temperature Difference in Co-Cross-Flow Heat Exchangers, Master thesis, Southern Methodist University, June, 1956.
Hiller, C. C. and Glicksman, L. R., 1976, "Improving Heat Pump Performance via Compressor Capacity Control - Analysis and Test," Report No. 24525-96, Heat Transfer Laboratory, Massachusetts Institute of Technology, 1976.

Holman, J. P., 1986, Heat Transfer, 6th Ed. McGrawHill, pp.554.

Kays, W. M., and London, A. L., 1984, Compact Heat Exchangers, 3rd Ed. McGraw-Hill.

Kline, S. J., and McClintock, F. A., 1953, "Describing Uncertainties in Single Sample Experiments," Mechanical Engineering, Vol 75, pp. 3-8. 
Mason, J. L., 1955, "Heat Transfer in Cross Flow," Proceedings of the Second U.S. National Congress of Applied Mechanics, ASME, New York, N. Y., pp. 801803.

Nicole, F. J. L., 1972, Mean Temperature Difference in Cross-Flow Heat Exchanger Applied to Multipass AirCooled Fin-Tube Units with A Finite Number of Rows, Ph.D. dissertation, University of Pretoria, November, 1972.

Nusselt, W., 1911, "Der Wărmeubergang im Kreuzstrom," Zeitschrift des Vereines deutscher Ingenieure, Vol 55, pp. 2021-2024.

Stevens, R. A., 1956, "Mean Temperature Difference in Counter-Cross-Flow Heat Exchangers, "Master Thesis, Southern Methodist University, June, 1956.

Stevens, R. A., Fernandez, J., and Wolf, J. R., 1957, "Mean-Temperature Difference in One, Two, and ThreePass Crossflow Heat Exchangers," Transactions of the American Society of Mechanical Engineers, February 1957, pp.287-297. 